\title{
Trifactorial Influence-Antisperm Antibody, Anti-Chlamydia Antibodies, and Thyroid Levels in Infertility
}

\author{
Sopia A Rajamanickam¹, Joseph PI Danislas², Kalyani Mohanram³ ${ }^{3}$, Shanthi Dinakaran ${ }^{4}$, Allen J Henry ${ }^{5}$
}

\begin{abstract}
Aim and objective: The present study determines the incidence of anti-Chlamydia antibodies (ACA), antisperm antibody (ASA), and thyroid levels in serum of infertility patients and statistically determines the significance of all three study parameters.

Materials and methods: A cross-sectional study was conducted on volunteers of 190 patients both male and female reporting to the Infertility Clinic of hospital and 178 patients including pregnant women patients were used as control. Serum from patients was collected and analyzed for the presence of anti-Chlamydia antibodies, ASA, serum T3, T4, and thyroid-stimulating hormone (TSH) levels by enzyme-linked immunosorbent assay (ELISA).

Results: Infertility patients representing $12.6 \%$ of the study population tested positive for anti-Chlamydia antibodies. $21.6 \%$ of 190 patients had high ASA levels and these levels were found to be statistically significant $p<0.001$ when compared with control. Elevated thyroid levels of the study population observed as increased T3 in 26 patients and T4 in 18 patients with 16 patients having increased TSH and the increased levels of thyroid in infertility patients compared with control is statistically significant $p$ value $<0.01$. Correlation between all three study parameters is statistically significant [0.01 level (two-tailed)].

Conclusion: Significantly higher levels of anti-Chlamydia antibodies and ASA are found associated in infertile patients as is elevated T3, T4, and TSH. All three parameters together can cause infertility showing the multidimensional factors for the development of infertility.

Clinical significance: Patients with infertility should be screened for all three study parameters viz. ACA, ASA, and thyroid levels and subsequent treatment protocols to resolve all possible adverse results to within normal levels for the success of ART.

Research highlights

- The present study found higher levels of anti-Chlamydia antibody in patients with primary infertility compared with the control group indicating the strong association between chlamydial infections and infertility.

- The present study found higher levels of antisperm antibodies in the serum of patients with primary infertility compared with the control group implying a significant role for ASA and development of infertility.

- Thyroid disorders such as hypothyroidism due to elevated TSH and hyperthyroidism associated with increased total serum T3 or T4 are several times higher in infertility patients when compared with the general population providing evidence for thyroid imbalance and infertility.

- All three study parameters - anti-Chlamydia antibodies, ASA, and thyroid levels occurring together in any one patient may tend to cause infertility.

Keywords: Antisperm antibody, Chlamydia trachomatis, Cross-sectional study, Enzyme-linked immunosorbent assay, Infertility, T3, T4, Thyroidstimulating hormone.

International Journal of Infertility and Fetal Medicine (2021): 10.5005/jp-journals-10016-1223
\end{abstract}

\section{INTRODUCTION}

Infertility is described as the inability to conceive after normal unprotected sex for more than a year. Infertility may be due to abnormality in one or rarely both partners.' One of the six major causes of infertility in males is immunological factors. Immunological factors include immune disorders arising due to sharing of antigens with similarity by semen and infectious agents. Chlamydia trachomatis is one of the bacterial agents that possess antigens when exposed to the immune system leads to the development of ASA both $\lg G$ and $\lg A$. The continued presence of antibodies in serum and secretions leads to immune infertility. ${ }^{2}$

WHO estimates that $>376$ million sexually transmitted bacterial infections occur annually across the world. These infections are caused by 30 different bacteria and a wide variety of viruses. Infection with C. trachomatis is the most common among bacterial infections accounting for 127 million cases globally every year. Chlamydia trachomatis is an intracellular parasite and cannot be isolated in routine culture methods. Most of the patients with chlamydial infections are asymptomatic. The method of detection of chlamydial infections is enzyme-linked immunosorbent assay
${ }^{1}$ Department of Microbiology, ACS Medical College and Hospital, Chennai, Tamil Nadu, India

${ }^{2}$ Department of Microbiology, Karpaga Vinayaga Institute of Medical Sciences and Research Centre, Chennai, Tamil Nadu, India

${ }^{3}$ Department of Microbiology, Saveetha Medical College, Chennai, Tamil Nadu, India

${ }^{4}$ Department of Obstetrics and Gynecology, ACS Medical College and Hospital, Chennai, Tamil Nadu, India

${ }^{5}$ Department of Microbiology, Vels Institute of Science, Technology and Advanced Studies, School of Life Sciences, Chennai, Tamil Nadu, India

Corresponding Author: Allen J Henry, Department of Microbiology, Vels Institute of Science, Technology and Advanced Studies, School of Life Sciences, Chennai, Tamil Nadu, India, Phone: +91 6369917726, e-mail: velsmicrobiology@gmail.com

How to cite this article: Rajamanickam SA, Danislas JPI, Mohanram $\mathrm{K}$, et al. Trifactorial Influence-Antisperm Antibody, Anti-Chlamydia Antibodies and Thyroid Levels in Infertility. Int J Infertil Fetal Med 2021;12(3):69-72.

Source of support: Nil

Conflict of interest: None

() Jaypee Brothers Medical Publishers. 2021 Open Access This article is distributed under the terms of the Creative Commons Attribution 4.0 International License (https://creativecommons.org/licenses/by-nc/4.0/), which permits unrestricted use, distribution, and non-commercial reproduction in any medium, provided you give appropriate credit to the original author(s) and the source, provide a link to the Creative Commons license, and indicate if changes were made. The Creative Commons Public Domain Dedication waiver (http://creativecommons.org/publicdomain/zero/1.0/) applies to the data made available in this article, unless otherwise stated. 
(ELISA) methods or by polymerase chain reactions. Chlamydia trachomatis causes repeat infections and has sequelae of infertility if left untreated. The treatment of chlamydial infection is simple involving a single drug regimen. The early diagnosis and successful treatment of $C$. trachomatis infection are crucial to the prevention of infertility associated with such prolonged infection. ${ }^{3}$

Antisperm antibody of class IgG in the blood of both males and females or IgA in vaginal secretions of women leads to immune infertility. The major cause of the development of ASA is abnormal sexual practices resulting in the exposure of seminal antigens to the immune system of the host. The other cause for immune infertility is the persistence of vaginitis and resultant crossing of blood tubal barrier by bacterial infectious agents not least of which is $C$. trachomatis. ${ }^{4}$ The diagnosis of chlamydial infections is by polymerase chain reaction for specific DNA in tissue samples or ELISA for antibody detection and quantitation in serum. PCR-based methods are time-consuming and generally done for research purposes whereas ELISA is more rapid and suitable to diagnose infections or the presence of antibodies. ${ }^{5}$

Thyroid levels especially pituitary gland secretion-thyroidstimulating hormone (TSH) and thyroid secretions-T3 (an inactive form of thyroid or triiodothyronine) or T4 (active form of thyroid or thyroxine) influence the fertility levels particularly in women and to a fewer degree men. Women in infertile couples are prone to ovulatory dysfunctions (OD) for which abnormal thyroid levels are one of the predisposing factors. Menstrual cycle changes are more common among women of infertile couples compared to women in the general population. ${ }^{6}$

\section{Materials and Methods}

The present cross-sectional study was performed on patients attending the Infertility Clinic of a Hospital in India from April 2017 to March 2019. The study was approved by the institutional Ethics Committee. Informed consent was obtained from the study population both patients attending the infertility clinic and outpatients representing the general population. Demographic data regarding age, education status, occupation, and personnel details documented. Complete information related to infertility status-primary or secondary, past history of pregnancies, menstrual history, previous infections, and antibiotic uptake was recorded and a detailed physical examination of the patient was done by the gynecologist. Blood was collected following venepuncture by a phlebotomist and separated serum stored at $-20^{\circ} \mathrm{C}$ until testing.

Assuming a $15 \%$ rate of positivity and $85 \%$ rate of detection with a 0.01 significance level the sample size was determined to be 190. A total of 190 patients both male and female reporting to infertility clinics with primary infertility were included in the study. Females below the age of 19 years and above 45 years, high-risk patients, a recent history of antibiotic treatment, and personnel associated with the study were excluded. One hundred and seventy-eight general population patients acted as a control group for anti-Chlamydial and antisperm antibody test and 147 patients in the general population served as a control for thyroid studies. Infertility was defined as the inability to conceive after 1 year of unprotected sex.

Enzyme-linked immunosorbent assay: IgG antibodies in serum specific to $C$. trachomatis antigens were, if present, quantified by antibody capture method using TMB substrate following the protocols of the commercial kit manufacturer-Calbiotech, USA and result interpreted and recorded. Serum IgG antisperm antibodies were detected using the solid-phase sandwich enzymeimmunoassay method of Bioserve Diagnostics, Germany.

Standard immunodiagnosis and quantitation of TSH by sandwich ELISA method and serum levels of T3 or T4 by competitive ELISA method was performed as per the instructions of the kit manufacturer Cortez Diagnostics, Inc., USA.

\section{Results}

The study population of 190 patients reporting to the fertility center tested for serum levels of antisperm antibodies the number of samples that tested negative was 149 (78.4\%) and those that tested positive was 41 (21.6\%). One hundred and seventy-eight patients from the control group, the number of samples identified with antisperm antibodies was 4 (2.2\%) and the remaining 174 (97.8\%) tested negative. This difference in anti-Chlamydia antibodies between the two groups' samples was found to be statistically significant $(p<0.001)$. There is no statistically significant association between antisperm antibody and anti-Chlamydia antibody (Table 1).

Fisher's exact test of the data in Table 1 determined that out of 190 serum samples from patients reporting to the infertility center, the number that tested negative for anti-Chlamydia antibodies was $166(87.4 \%)$ and those that tested positive was 24 (12.6\%) and from 178 samples from the control group, the number of samples identified with anti-Chlamydia antibodies was 6 (3.4) and the remaining 172 (96.6\%) tested negative. This difference in anti-Chlamydia antibodies between the two groups of samples was found to be statistically significant $(p=0.001)$.

Among the 190 participants of the study, 26 (13.7\%) of the infertile patients reporting to the fertility center had higher levels of total serum T3 or hyperthyroidism, on the other hand, only 2 (1.4\%) of the general population had hyperthyroidism due to elevated total T3. The differences were found to be significant statistically ( $p$ value $<0.05)$. Out of 190 study participants, $18(9.5 \%)$ of the patients with infertility reporting to the fertility center had hyperthyroidism as detected with higher total serum T4 level, while only 2 (1.4\%) of the general population had hyperthyroidism based on higher T4 levels. The differences were found to be significant statistically ( $p$ value $<0.05)$. Sixteen $(8.4 \%)$ out of the study group comprising 190 patients reporting to the fertility center had hypothyroidism as a result of elevated total serum TSH but only $3(2 \%)$ of the general

Table 1: Intergroup comparison of serum anti-Chlamydia antibody levels and serum antisperm antibody levels

\begin{tabular}{|c|c|c|c|c|c|c|}
\hline \multirow[b]{3}{*}{ Group } & \multicolumn{2}{|c|}{$\begin{array}{c}\text { Serum anti-Chlamydia } \\
\text { antibody }\end{array}$} & & \multicolumn{2}{|c|}{ Serum antisperm antibody } & \multirow[b]{3}{*}{$p$ value } \\
\hline & Negative & Positive & & Negative & Positive & \\
\hline & $n(\%)$ & $n(\%)$ & $p$ value & $n(\%)$ & $n(\%)$ & \\
\hline Patients reporting to fertility center & $166(87.4)$ & $24(12.6)$ & 0.001 & $149(78.4)$ & $41(21.6)$ & $<0.001$ \\
\hline Control group & 172 (96.6) & $6(3.4)$ & & $174(97.8)$ & $4(2.2)$ & \\
\hline
\end{tabular}


population had hypothyroidism. The differences were found to be significant statistically ( $p$ value $<0.05$; Table 2 ). There was a statistically significant positive correlation between T3 and T4 (0.181) as determined by Spearman's two-tailed test of significance. Statistically significant correlation-Pearson's two-tailed; $p<0.01$ between ASA, anti-Chlamydia antibody, and thyroid is present. Pearson's correlation of all three factors is significant at 0.01 level (two-tailed) (Table 3).

\section{Discussion}

The present study determined that the level of IgG anti-Chlamydia antibody in infertile patients both male and female is 3.7 times higher when compared with control. This increase in anti-Chlamydia antibody in infertile patients is significant statistically indicating a probable role of chlamydial infections both acute or older and development of infertility. The detection of IgG anti-Chlamydia antibodies is advantageous as $C$. trachomatis infections ${ }^{7}$ are predominantly asymptomatic and not part of empiric detection protocols. Chlamydia trachomatis infections cause pelvic inflammatory disease (PID) that is can lead to infertility in females as described in studies by Odusolu et al. ${ }^{8}$ as well as tubal disorders as reported by Singh et al. ${ }^{9}$ Our study documents a $>10$ times higher prevalence of ASA in the study population with the increased level of ASA being significant. Immune infertility due to continued and persistent levels of ASA in males and implication of ASA in polycystic ovarian syndrome (PCOS) and the attendant complications in treatments to resolve infertility especially subclinical infertility are documented in the study by Dhama et al. ${ }^{10}$ and findings also strongly reiterate the stated possible adverse outcomes due to increased ASA Piroozmand et al. ${ }^{11}$

Our study determined that there is 11 times increase in hyperthyroidism in the study population compared with control out of which elevated T3 levels contributed $59.1 \%$ with increased T4 levels accounting for the remaining 40.9\%. Hypothyroidism due to higher TSH levels in the present study is 9 times higher in the study population. Thyroid disorders are known to cause subfertility in $3-5 \%$ of infertility cases and abnormal TSH levels are implicated in obstructive disorders and disturbed menstrual cycle as per the studies documented by Jefferys et al. ${ }^{12}$ and in our study 4 out of 16 women in an infertile couple reported abnormal menstrual cycle which is in agreement with the mentioned study. Alteration in sperm parameters such as impaired sperm motility, abnormal sperm structure azoospermia is reported in $12 \%$ of male participants and this is similar to the study by Karaca and Akpak $^{13}$ wherein they reported that the thyroid disorders and the associated complications in conceiving include altered

Table 2: Total serum T3, T4, and TSH levels and their significance

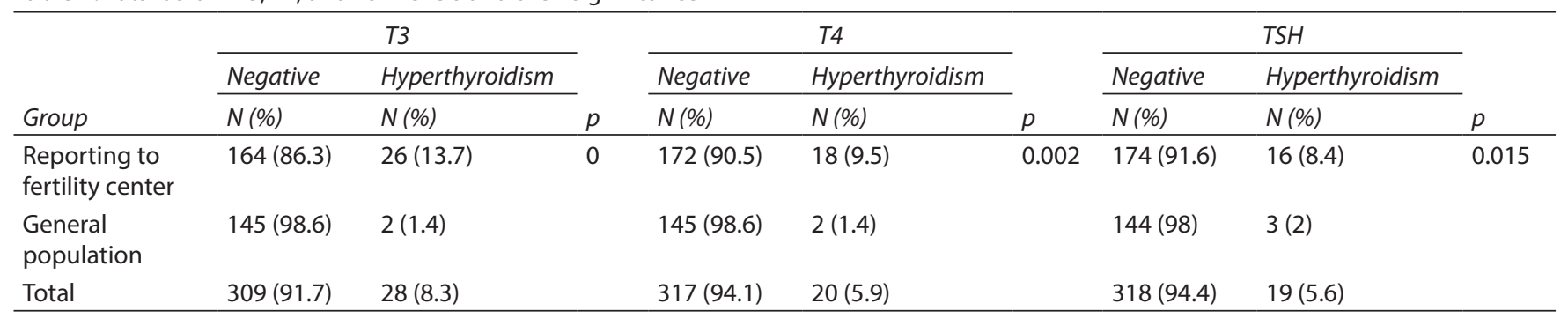

Table 3: Correlation between anti-Chlamydia antibodies level, ASA, and thyroid level in infertility patients

\begin{tabular}{|c|c|c|c|c|c|c|c|}
\hline & & Age & $\begin{array}{l}\text { Serum anti- } \\
\text { chlamydia } \\
\text { antibody }\end{array}$ & $\begin{array}{l}\text { Serum } \\
\text { antisperm } \\
\text { antibody }\end{array}$ & T3 & T4 & $\mathrm{TSH}$ \\
\hline \multirow[t]{3}{*}{ Age } & Pearson correlation & 1 & -0.084 & -0.063 & -0.084 & 0.001 & 0.027 \\
\hline & Sig. (two-tailed) & & 0.322 & 0.462 & 0.322 & 0.994 & 0.747 \\
\hline & $N$ & 140 & 140 & 140 & 140 & 140 & 140 \\
\hline \multirow[t]{3}{*}{ Serum anti-Chlamydia antibody } & Pearson correlation & -0.084 & 1 & $0.291^{*}$ & 0.100 & -0.004 & -0.146 \\
\hline & Sig. (two-tailed) & 0.322 & & 0.000 & 0.240 & 0.961 & 0.085 \\
\hline & $N$ & 140 & 140 & 140 & 140 & 140 & 140 \\
\hline \multirow[t]{3}{*}{ Serum antisperm antibody } & Pearson correlation & -0.063 & $0.291^{*}$ & 1 & -0.010 & -0.020 & -0.131 \\
\hline & Sig. (two-tailed) & 0.462 & 0.000 & & 0.911 & 0.812 & 0.123 \\
\hline & $N$ & 140 & 140 & 140 & 140 & 140 & 140 \\
\hline \multirow[t]{3}{*}{ T3 } & Pearson correlation & -0.084 & 0.100 & -0.010 & 1 & 0.152 & -0.111 \\
\hline & Sig. (two-tailed) & 0.322 & 0.240 & 0.911 & & 0.072 & 0.193 \\
\hline & $N$ & 140 & 140 & 140 & 140 & 140 & 140 \\
\hline \multirow[t]{3}{*}{ T4 } & Pearson correlation & 0.001 & -0.004 & -0.020 & 0.152 & 1 & -0.022 \\
\hline & Sig. (two-tailed) & 0.994 & 0.961 & 0.812 & 0.072 & & 0.794 \\
\hline & $N$ & 140 & 140 & 140 & 140 & 140 & 140 \\
\hline \multirow[t]{3}{*}{ TSH } & Pearson correlation & 0.027 & -0.146 & -0.131 & -0.111 & -0.022 & 1 \\
\hline & Sig. (two-tailed) & 0.747 & 0.085 & 0.123 & 0.193 & 0.794 & \\
\hline & $N$ & 140 & 140 & 140 & 140 & 140 & 140 \\
\hline
\end{tabular}

${ }^{*}$ Correlation is significant at the 0.01 level (two-tailed) 
sperm characters with hormonal imbalance affecting the female reproductive system.

The present study documents that there is no combined influence of ASA and anti-Chlamydia antibodies on infertility although individually they may contribute to the development of infertility. A positive correlation is present between all three study parameters namely ASA, anti-Chlamydia antibody, and thyroid disorders indicate the multidimensional aspect of all types of infertility-primary, secondary, or subclinical. This validates the previous studies done by Vander Borght and Wyns ${ }^{14}$ which trace the multiple factors associated with infertility. We also recommend that ASA and especially anti-Chlamydia antibody evaluation along with thyroid function tests of patients reporting to infertility clinics for successful treatment outcomes.

\section{Conclusion}

The present study found higher levels of anti-Chlamydia antibody and ASA in patients with primary infertility. Thyroid disorders such as hypothyroidism due to elevated TSH and hyperthyroidism associated with increased total serum T3 or T4 are several times higher in infertility patients when compared with the general population. All three study parameters-anti-Chlamydia antibodies, ASA, and thyroid levels occurring together tend to cause infertility strengthening the multifarious nature of development of infertility. Early detection and management of chlamydial infections are warranted for preventing the development of infertility in women.

\section{Clinical Significance}

All three study parameters were individually found to be significantly higher in infertility patients substantiating the inclusion of all three parameters during the screening of such patients. The success of infertility treatment in patients with positive outcome of study parameters will require treatment protocols to resolve these issues and routine screening to ascertain prognosis.

\section{ACKnowledgments}

The authors wish to acknowledge the management and staff of ACS Medical College, Tamil Nadu for their consent and cooperation to carry out this study.

\section{References}

1. Zegers-Hochschild F, Adamson GD, Dyer S, et al. The international glossary on infertility and fertility care. Human Reproduct 2017;32(9):1786-1801. DOI: 10.1093/humrep/dex234.

2. Cui $D$, Han G, Shang $Y$, et al. Antisperm antibodies in infertile men and their effect on semen parameters: a systematic review and meta-analysis. Clinica Chimica Acta 2015;444:29-36. DOI: 10.1016/j. cca.2015.01.033.

3. World Health Organization, Report on global sexually transmitted infection surveillance 2018.

4. Menon S, Timms P, Allan JA, et al. Human and pathogen factors associated with Chlamydia trachomatis-related infertility in women. Clin Microbiol Rev 2015;28(4):969-985. DOI: 10.1128/CMR.00035-15.

5. Fu J, Yao R, Luo Y, et al. Immune infertility should be positively diagnosed using an accurate method by monitoring the level of AntiACTL7a antibody. Scienti Rep 2016;6:22844. DOI: 10.1038/srep22844.

6. Unuane D, Velkeniers B. Impact of thyroid disease on fertility and assisted conception. Best Pract Res Clin Endocrinol Metabol 2020;30(4):101378. DOI: 10.1016/j.beem.2020.101378.

7. Rashidi BH, Chamani-Tabriz L, Haghollahi F, et al. Effects of Chlamydia trachomatis infection on fertility; a case-control study. J Reproduct Infertil 2013;14(2):67.

8. Odusolu PO, Edet EE, Emechebe $\mathrm{Cl}$, et al. Prevalence of Chlamydia trachomatis immunoglobulin $\mathrm{G}$ antibody in infertile women in Calabar. Afr J Med Health Sci 2016;15(2):74. DOI: 10.4103/23845589.198319.

9. Singh S, Bhandari S, Agarwal P, et al. Chlamydia antibody testing helps in identifying females with possible tubal factor infertility. Int J Reproduct BioMed 2016;14(3):187. DOI: 10.29252/ijrm.14.3.187.

10. Dhama K, Chakraborty S, Samad HA, et al. Role of antisperm antibodies in infertility, pregnancy, and potential for contraceptive and antifertility vaccine designs: research progress and pioneering vision. Vaccines 2019;7(3):116. DOI: 10.3390/vaccines7030116.

11. Piroozmand A, Mousavi Nasab SD, Erami M, et al. Distribution of human papillomavirus and antisperm antibody in semen and its association with semen parameters among infertile men. J Reproduct Infertil 2020;21(3):183-188.

12. Jefferys A, Vanderpump M, Yasmin E. Thyroid dysfunction and reproductive health. Obstet Gynaecol 2015;7(1):39-45. DOI: 10.1111/ tog.12161.

13. Karaca N, Akpak YK. Thyroid disorders and fertility. Int J Res Med Sci 2015;3:1299-1304. DOI: 10.18203/2320-6012.ijrms20150135.

14. Vander Borght $M$, Wyns $C$. Fertility and infertility: definition and epidemiology. Clin Biochem 2018;1(62):2-10. DOI: 10.1016/j. clinbiochem.2018.03.012. 